\title{
Using Hydrogen Influences to Control the Greenhouse Gas Emissions from Methane-Hydrogen Turbulent Flame
}

\author{
Majid Ghafourizadeh ${ }^{1}$, Masoud Darbandi ${ }^{1}$, Gerry E. Schneider ${ }^{2}$ \\ ${ }^{1}$ Department of Aerospace Engineering, \\ Centre of Excellence in Aerospace Systems, \\ Sharif University of Technology, Tehran, P. O. Box 11365-8639, Iran \\ darbandi@sharif.edu; majid.ghafourizadeh@gmail.com \\ ${ }^{2}$ Department of Mechanical and Mechatronics Engineering, \\ University of Waterloo, Waterloo, Ontario, N2L 3G1, Canada \\ gerry.schneider@uwaterloo.ca
}

\begin{abstract}
In this paper, we study the effects of hydrogen enrichment and depletion on greenhouse gas emissions from a bluff-body stabilized turbulent flame fed with a mixture of methane and hydrogen as its fuel. To do this study, we use the chemical mechanism consisting of 70 species and 463 elementary reactions, adopt flamelet combustion model to surmount the closure problem of chemical source terms within the classical Reynolds-Stress-Model RSM turbulence approaches. We employ the two-equation standard $\kappa-\varepsilon$ turbulence model with round jet corrections incorporated with suitable wall functions. The turbulence-chemistry interaction is taken into account using the presumed-shape probability density functions PDFs. The radiation effects of the most important radiating species are taken into account supposing an optically-thin flame. Using such detailed-chemistry approach, we first simulate a benchmark burner to evaluate the capability of our developed numerical simulation to predict the flame structure. Second, we compare the achieved distributions of temperature and species concentrations within the flame with the available measurement data. The achieved results indicate that our numerical simulation predicts the temperature and species concentration distributions very accurately and that the achieved results are in great agreement with the experimental data. Then, we investigate the effects of enriching fuel on the achieved results. We also compare the results with those of the benchmark case in terms of the greenhouse gas emissions right at the outlet of combustor. Our findings show that the greenhouse gas emissions can be reduced via using suitable hydrogen enrichment techniques. Alternatively, greenhouse gas emissions can increase with hydrogen fuel depletion.
\end{abstract}

Keywords: Numerical simulation, Hydrogen enrichment/depletion, Greenhouse gases, Air pollution, Chemical kinetics, Methane-hydrogen flame

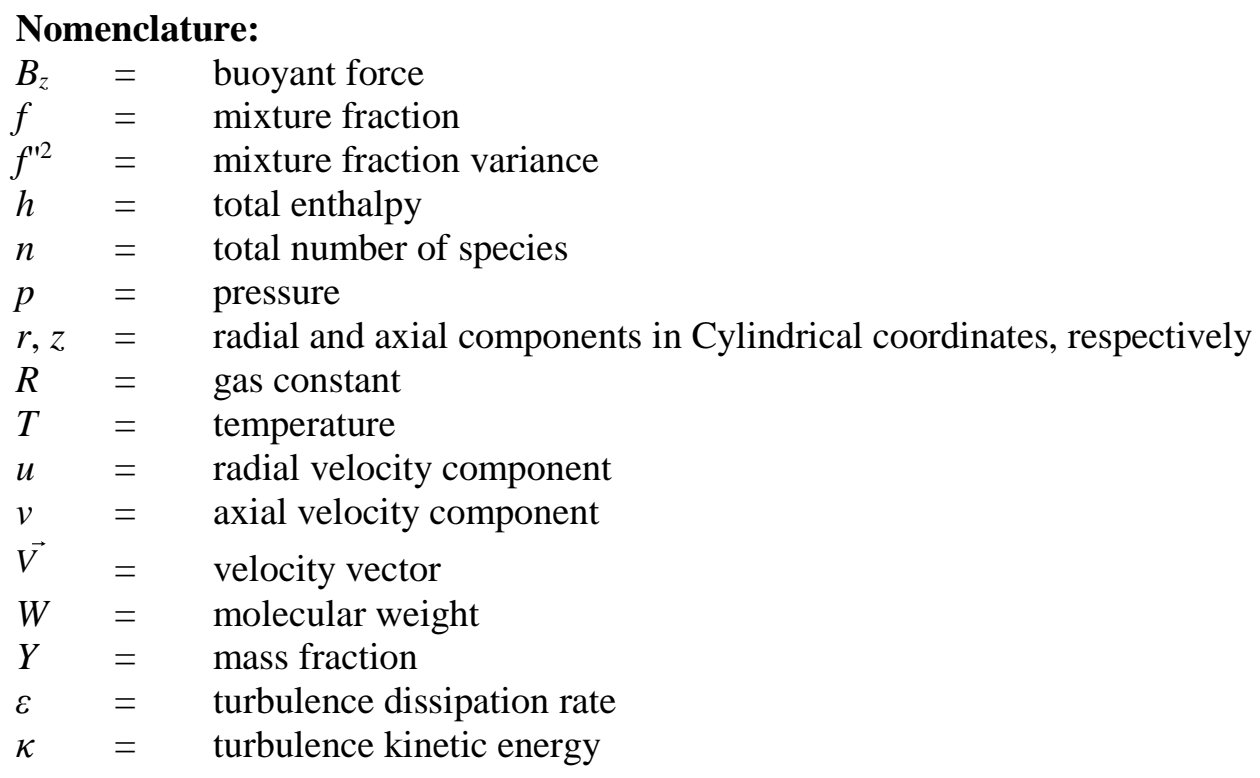




$\begin{array}{lll}\mu & = & \text { molecular viscosity coefficient } \\ \rho & = & \text { mixture density } \\ \chi & = & \text { scalar dissipation rate }\end{array}$

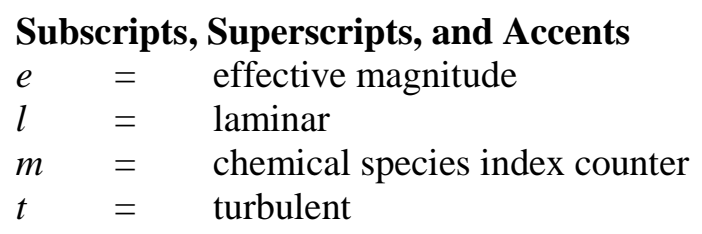

\section{Introduction}

The non-premixed flames have vast applications in many combustion chambers and industrial burners. Literature shows that there are a large number of researchers, which carefully investigate such flames fed with various hydrocarbon fuel types. Due to major progresses achieved in modelling the turbulent pilot-stabilized jet flames with parabolic-streaming flows [1], the researchers, i.e. either experimental workers or computational fluid dynamics CFD scientists, are now focusing on turbulent flames having more complex flow behaviours. Among them, the bluff-body stabilized flows are considered as very attractive ones because of their vast applications in many practical engineering problems, e.g. the bluffbody combustors. As known, the turbulence generated behind the bluff body becomes significant and it can improve the mixing characteristics and it prevents the flame blow-off at high flow velocities. The current bluff-body burner model has simple and well-defined boundary conditions. It is also capable of stabilizing the flames with complicated recirculating zones. This flame holder model is an interesting model problem for industrial flow cases. It can be also utilized as a benchmark problem by the investigators in various combustion field applications.

Among different aspects of combustion process, one major standpoint has been to control the emission of air pollutants. The air pollutants, e.g. greenhouse gases, have dangerous impacts on human health and environmental safety such as the global warming and ozone destruction perspectives. So, it is necessary to control such emissions producing in such low-pollutant burners, e.g., introducing alternative fuels, oxidants, or blended fuels.

Literature shows that the recent researchers have dedicated their attentions and efforts to hydrogen study from different points including its production, sources, storage, and energy systems and technologies [2-4]. Literature also shows that there is less efforts to pay attention to investigate the hydrogen combustion itself. Alternatively, such studies have mainly focused on NOx emissions from such flames [5-8]. So, there is the lack of knowledge in area of the blended fuels combustion and their greenhouse gases emissions. In this work, we simulate a bluff-body burner, an O-ring type flame holder, to validate the current developed numerical method and to simulate the turbulent nonpremixed flames in such burners using an advanced detail-chemistry modelling. In other words, we employ a detailed chemistry model containing 463 reversible chemical reactions between 70 chemical species. As raised before, we use the flamelet model and the presumed-shape PDFs to close the chemical source terms' closure and the chemistry-turbulence interaction, respectively. We use the standard $\kappa-\varepsilon$ turbulence model with round jet corrections and take into account the radiation effects assuming the optically-thin gas assumptions. We solve the bluff-body stabilized $\mathrm{CH}_{4} / \mathrm{H}_{2}$-air nonpremixed flame, to assess the accuracy of our achieved numerical solution in predicting the flame structure. We compare our numerical results with the experimental data for the distributions of temperature and species concentrations within the flame. The comparisons indicate that the current numerical accuracy is sufficiently good and that the current method satisfactorily predicts the flame structure. Then, we change the concentration of hydrogen in the fuel to study its effects on the emissions of greenhouse gases from the flame. Our study shows that the hydrogen enrichment/depletion can affect the magnitudes of carbon monoxide and dioxide, methane, and water vapour emissions at the combustion chamber outlet.

\section{The Governing Equations}

The fluid flow conservation laws consisting of the continuity, $r$-momentum, and $z$-momentum are given by

$$
\nabla \cdot(\rho \mathbf{V})+\rho \frac{\mathrm{u}}{\mathrm{r}}=0
$$




$$
\begin{gathered}
\nabla \cdot(\rho \mathbf{V u})=-\frac{\partial \mathrm{p}}{\partial \mathrm{r}}+\nabla \cdot\left(\mu_{\mathrm{e}} \nabla \mathrm{u}\right)+\mu_{\mathrm{e}} \frac{1}{\mathrm{r}} \frac{\partial \mathrm{u}}{\partial \mathrm{r}}-\mu_{\mathrm{e}} \frac{\mathrm{u}}{\mathrm{r}^{2}} \\
\nabla \cdot(\rho \mathbf{V v})=-\frac{\partial \mathrm{p}}{\partial \mathrm{z}}+\nabla \cdot\left(\mu_{\mathrm{e}} \nabla \mathrm{v}\right)+\mu_{\mathrm{e}} \frac{1}{\mathrm{r}} \frac{\partial \mathrm{v}}{\partial \mathrm{r}}+\mathrm{B}_{\mathrm{z}}
\end{gathered}
$$

where $\mu_{e}=\mu_{l}+\mu_{t}$ and $B_{z}=-\rho g$. The transport equations for turbulence quantities are given by

$$
\begin{gathered}
\nabla \cdot(\rho \mathbf{V} \kappa)=\nabla \cdot\left(\frac{\mu_{\mathrm{e}}}{\sigma_{\kappa}} \nabla \kappa\right)+\frac{\mu_{\mathrm{e}}}{\sigma_{\kappa}} \frac{1}{\mathrm{r}} \frac{\partial \kappa}{\partial \mathrm{r}}+\mathrm{G}_{\kappa}-\rho \varepsilon \\
\nabla \cdot(\rho \mathbf{V} \varepsilon)=\nabla \cdot\left(\frac{\mu_{\mathrm{e}}}{\sigma_{\varepsilon}} \nabla \varepsilon\right)+\frac{\mu_{\mathrm{e}}}{\sigma_{\varepsilon}} \frac{1}{\mathrm{r}} \frac{\partial \varepsilon}{\partial \mathrm{r}}+\frac{\varepsilon}{\kappa}\left(\mathrm{c}_{1} \mathrm{G}_{\kappa}-\mathrm{c}_{2} \rho \varepsilon\right)
\end{gathered}
$$

where $G_{\kappa}=\mu_{e}\left\{2\left[(\partial v / \partial z)^{2}+(\partial u / \partial r)^{2}+(u / r)^{2}\right]+[(\partial v / \partial r)+(\partial u / \partial z)]^{2}\right\}, \mu_{t}=c_{d} \rho \kappa^{2} / \varepsilon, \sigma_{\kappa}=0.9, \sigma_{\varepsilon}=1.22, c_{1}=1.44, c_{2}=1.84$, and $c_{d}=0.09$ [9]. As known, the wall function implementation is a general idea to describe the flow behaviour near the solid walls due to dominant viscous effects there.

To surmount the closure problem of chemical source terms within the RSM turbulence models, the flamelet models are considered as the promising approaches via using the detailed chemical kinetics mechanisms [10]. In this study, we choose the detailed kinetic scheme of Qin [11], which consists of 70 chemical species and 463 chemical reactions. The transport equations for the first two moment of mixture fractions are given by

$$
\begin{gathered}
\nabla \cdot(\rho \mathbf{V f})=\nabla \cdot\left(\frac{\mu_{\mathrm{e}}}{\sigma_{\mathrm{f}}} \nabla \mathrm{f}\right)+\frac{\mu_{\mathrm{e}}}{\sigma_{\mathrm{f}}} \frac{1}{\mathrm{r}} \frac{\partial \mathrm{f}}{\partial \mathrm{r}} \\
\nabla \cdot\left(\rho \mathbf{V \mathrm { f } ^ { \prime 2 }}\right)=\nabla \cdot\left(\frac{\mu_{\mathrm{e}}}{\sigma_{\mathrm{f}}} \nabla \mathrm{f}^{\prime 2}\right)+\frac{\mu_{\mathrm{e}}}{\sigma_{\mathrm{f}}} \frac{1}{\mathrm{r}} \frac{\partial \mathrm{f}^{\prime \prime}}{\partial \mathrm{r}}+\mathrm{c}_{\mathrm{g}} \mu_{\mathrm{e}}(\nabla \mathrm{f})^{2}-\rho c_{\chi} \frac{\varepsilon}{\kappa} \mathrm{f}^{\prime 2}
\end{gathered}
$$

where $c_{g}=2.86, c_{\chi}=2$, and the turbulent Schmidt number $\sigma_{f}$ is assumed to be 0.85 . The turbulence-chemistry interaction is taken into account using the presumed-shape probability density functions PDFs. The results from precomputed laminar flamelets and turbulent statistics can be tabulated as a three-dimensional lookup table such that all thermo-chemical quantities over the solution domain can be obtained from this table [12].

Assuming a unit Lewis number, the enthalpy equation is given by

$$
\nabla \cdot(\rho \mathbf{V h})=\nabla \cdot\left(\frac{\mu_{\mathrm{e}}}{\sigma_{\mathrm{h}}} \nabla \mathrm{h}\right)+\frac{\mu_{\mathrm{e}}}{\sigma_{\mathrm{h}}} \frac{1}{\mathrm{r}} \frac{\partial \mathrm{h}}{\partial \mathrm{r}}+\mathrm{q}_{\mathrm{rad}}
$$

in which the turbulent Prandtl numbers $\sigma_{h}$ is assumed to be 0.85 . Thermal radiation of gases is taken into account assuming an optically thin flame. Finally, the density is obtained from the equation of state using $p=$ $\rho \operatorname{RT} \sum_{\mathrm{m}=1}^{\mathrm{n}} \mathrm{Y}_{\mathrm{m}} / \mathrm{W}_{\mathrm{m}}$.

\section{Computational Method}

Back to our past experiences [13, 14], we choose a hybrid finite-volume-element FVE method to perform our study. The solution domain is broken into a large number of quadrilateral elements. Nodes, located at the element vertices, are the locations of all unknown variables. To benefit from a cell-centred finite-volume FV method, each element is divided into four sub-quadrilaterals. The finite volume cells are then constructed from the proper assemblages of each four subquadrilaterals $[13,14]$. Using the physical influence advective kinetics scheme PIS, we eventually arrive a few systems of linear algebraic equations, which need to be solved individually. In this regard, we obtain eight equations corresponding to eight unknowns. So, the set of derived linear algebraic equations does not become under- or over-determined. We construct two sub-global stiffness matrices, corresponding to the hydrodynamics parameters and the thermo-chemical quantities. 
Each of these sub-global stiffness matrices can be solved within each iteration using a bi-implicit approach. The details of this computational method can be found in Refs. [13, 14].

\section{The Benchmark Test Case and Validation}

The turbulent non-premixed flame of $\mathrm{CH}_{4} / \mathrm{H}_{2}$ stabilized on an axisymmetric bluff-body burner is chosen to verify the accuracy of our numerical method. We employ the experimental conditions of Dally et al. [15] to perform our simulations. Figure 1 shows the configuration of the bluff-body burner. Because of the symmetry of problem, we consider a rectangular solution domain applying the symmetry boundary conditions at the centre line. The computational domain has $0.1 \mathrm{~m} \times 0.7$ $\mathrm{m}$ dimensions, i.e. $R_{0}=0.1 \mathrm{~m}$ and $L=0.7 \mathrm{~m}$. The burner has a bluff-body inside with a diameter of $50 \mathrm{~mm}$. The fuel nozzle diameter is $3.6 \mathrm{~mm}$. This fuel nozzle injects the mixture of $\mathrm{CH}_{4} / \mathrm{H}_{2}(1: 1$ by volume $)$ as the fuel at a speed of $118 \mathrm{~m} / \mathrm{s}$ into the combustor. The oxidizer, i.e. the co-flow air stream, which consists of $23.3 \%$ oxygen and $76.7 \%$ nitrogen, enters into the combustor with a speed of $40 \mathrm{~m} / \mathrm{s}$. The initial temperatures of fuel and oxidizer are 298 and $300 \mathrm{~K}$, respectively.

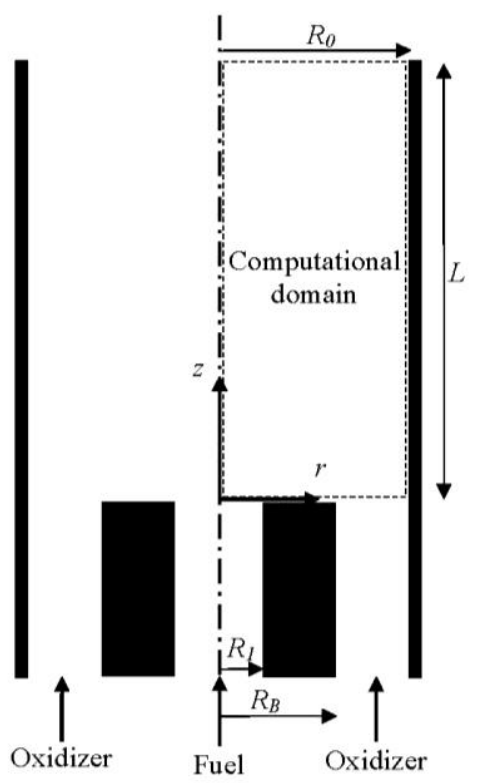

Fig. 1: The configuration of an O-ring-type flame holder placed in a combustion chamber [15].

To asses our numerical simulation in correct prediction of the above flame structure, we present the distributions of mixture fraction, temperature, and the mole fractions of different chemical species at different positions downstream of the flame inlet. Figure 2 shows the distributions of these quantities at $z=13,30,45,65,90$, and 120mm locations for the bluffbody stabilized $\mathrm{CH}_{4} / \mathrm{H}_{2}$ turbulent non-premixed flame. We use the black, red, orange, green, blue, and pink colours to indicate these sections, respectively. The current numerical solutions are compared with the experimental data of Dally et al. [15]. As observe there are greet agreements between the current solutions and the experiment. However, there are some slight discrepancies between them. Such discrepancies can be attributed to the weaknesses of turbulence and radiation models utilized in our simulation. For instance, the standard $\kappa-\varepsilon$ turbulence model does not perform well in simulating the flows, in which the intense adverse pressure gradients present. Additionally, the empirical constants of RSM turbulence approaches, including the standard $\kappa-\varepsilon$ turbulence model, are required to be adjusted properly in the cylindrical coordinates frame to warrant the correct prediction of recirculation zone specifications, i.e. the spreading rate, decay rate, and the length of recirculation zone [16]. Moreover, the optically-thin flame assumption used in the radiative heat transfer calculation can also lead to some possible slight discrepancies with the experimental data. Considering these points, we can readily claim that the current numerical simulation has shown sufficient accuracy in correct prediction of the bluff-body stabilized flame structure. 

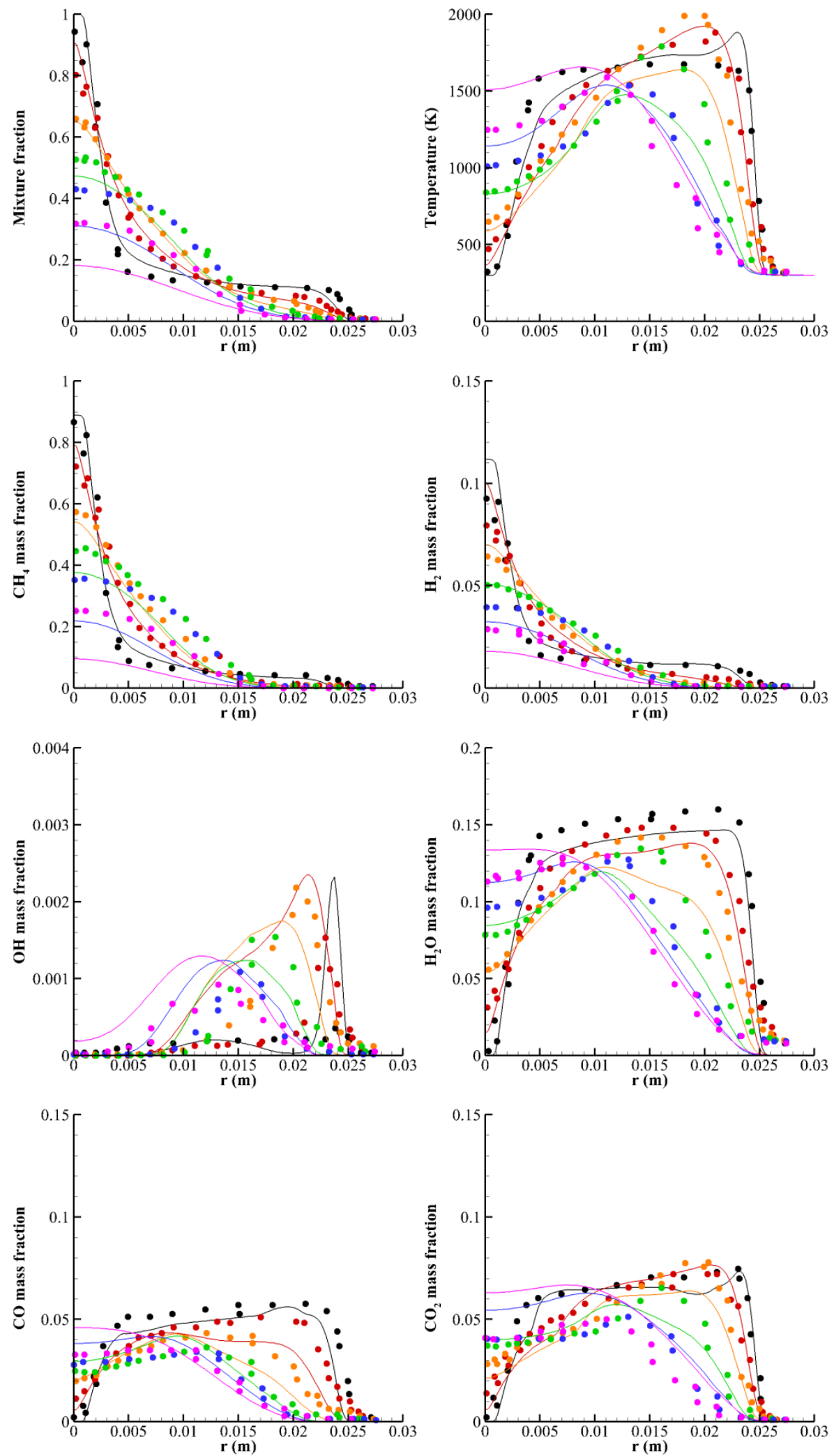

Fig. 2: The distributions of mixture fraction, temperature, and a few species mass fractions at $z=13,30,45,65,90$, and $120 \mathrm{~mm}$ in the bluff-body stabilized $\mathrm{CH}_{4} / \mathrm{H}_{2}$ turbulent non-premixed flame and comparison with the experimental data of Dally et al. [15]. 


\section{The Effects of Hydrogen Enrichment/Depletion on Greenhouse Gases Emissions}

Table 1 shows the effects of hydrogen mole fraction magnitude on the greenhouse gas emissions, including $\mathrm{CH}_{4}$, $\mathrm{H}_{2} \mathrm{O}$, CO, and $\mathrm{CO}_{2}$, from the preceding flame, see Fig. 1. In this regard, we first increase the amount of hydrogen mole fraction from $50 \%$ to $60 \%$ and $70 \%$ while reduce the mole fraction of methane form $50 \%$ to $40 \%$ and $30 \%$, respectively. Table 1 also shows the effects of hydrogen depletion on $\mathrm{CH}_{4}, \mathrm{H}_{2} \mathrm{O}, \mathrm{CO}$, and $\mathrm{CO}_{2}$ emissions. In this regard, the mole fraction of hydrogen is gradually decreased in a step-by-step manner from $50 \%$ to $40 \%$ and $30 \%$ while increasing the mole fraction of methane from $50 \%$ to $60 \%$ and $70 \%$, respectively. Comparing the hydrogen enrichment and depletion cases with each other, we can conclude that the greenhouse gas emissions would be reduced if the hydrogen is enriched in the methane fuel. Obviously, the $\mathrm{CH}_{4}, \mathrm{H}_{2} \mathrm{O}, \mathrm{CO}$, and $\mathrm{CO}_{2}$ emissions become serious if the methane mole fraction percentages is increased in the current methane-hydrogen flame.

Table 1: The mass-weighted average of species mass fractions at the combustor outlet with the hydrogen enrichment/depletion technique.

\begin{tabular}{|c|c|c|c|c|}
\hline Fuel & $\mathrm{CH}_{4}$ & $\mathrm{H}_{2} \mathrm{O}$ & $\mathrm{CO}$ & $\mathrm{CO}_{2}$ \\
\hline $\mathrm{CH}_{4}(30 \%)$ and $\mathrm{H}_{2}(70 \%)$ & $2.78 \mathrm{E}-30$ & $8.36 \mathrm{E}-04$ & $8.59 \mathrm{E}-09$ & $4.71 \mathrm{E}-04$ \\
\hline $\mathrm{CH}_{4}(40 \%)$ and $\mathrm{H}_{2}(60 \%)$ & $4.87 \mathrm{E}-09$ & $8.88 \mathrm{E}-04$ & $1.86 \mathrm{E}-06$ & $6.18 \mathrm{E}-04$ \\
\hline $\mathrm{CH}_{4}(50 \%)$ and $\mathrm{H}_{2}(50 \%)$ & $9.59 \mathrm{E}-08$ & $9.41 \mathrm{E}-04$ & $1.22 \mathrm{E}-05$ & $7.55 \mathrm{E}-04$ \\
\hline $\mathrm{CH}_{4}(60 \%)$ and $\mathrm{H}_{2}(40 \%)$ & $5.15 \mathrm{E}-07$ & $9.90 \mathrm{E}-04$ & $2.99 \mathrm{E}-05$ & $8.78 \mathrm{E}-04$ \\
\hline $\mathrm{CH}_{4}(70 \%)$ and $\mathrm{H}_{2}(30 \%)$ & $1.73 \mathrm{E}-06$ & $1.03 \mathrm{E}-03$ & $5.22 \mathrm{E}-05$ & $9.85 \mathrm{E}-04$ \\
\hline
\end{tabular}

\section{Conclusion}

A bluff-body stabilized turbulent nonpremixed flame, i.e. an O-ring-type flame holder, was simulated using an advanced detailed chemistry model. We utilized the laminar flamelet approach and the two-equation standard $\kappa-\varepsilon$ turbulence model to simulate the flame. We benefited from our past experiences in finite-volume element FVE method and used the physical influence scheme PIS formulations to calculate the cell-face fluxes. We chose the bluff-body stabilized flame burning $\mathrm{CH}_{4} / \mathrm{H}_{2}$ as our target test case. The accuracy of the developed method was assessed by comparing the achieved numerical solutions with the available experimental data. In other words, we compared the achieved distributions of temperature and species concentrations along different locations within the flame with those of experiment. The present results showed that there were great agreements with the measured data. Next, we studied the effect of hydrogen enrichment/depletion on the generated green gas emissions releasing into the surrounding atmosphere at the combustor outlet; including the $\mathrm{CH}_{4}, \mathrm{H}_{2} \mathrm{O}, \mathrm{CO}$, and $\mathrm{CO}_{2}$ emissions. Our study showed that the emissions of these greenhouse gases were strongly affected by the magnitude of hydrogen mole fraction. Indeed, the air pollution would be reduced considerably if the concentration of hydrogen is suitably increased in the fuel.

\section{Acknowledgements}

The authors would like to thank the financial support received from the Deputy of Research and Technology in Sharif University of Technology. The received financial support and help are greatly acknowledged.

\section{References}

[1] A. R. Masri, R. W. Dibble, and R. S. Barlow, "The Structure of Turbulent Nonpremixed Flames Revealed by RamanRayleigh-LIF Measurement," Progress in Energy and Combustion Science, vol. 22, pp. 307-362, 1996.

[2] S. Dunn, "Hydrogen Futures: toward a Sustainable Energy System," International Journal of Hydrogen Energy, vol. 27, pp. 235-264, 2002.

[3] A. Midilli, M. Ay, I. Dincer, and M. A. Rosen, "On Hydrogen and Hydrogen Energy Strategies: I: Current Status and Needs," Renewable and Sustainable Energy Reviews, vol. 9, pp. 255-271, 2005.

[4] J. R. Bartels, M. B. Pate, and N. K. Olson, "An Economic Survey of Hydrogen Production from Conventional and Alternative Energy Sources," International Journal of Hydrogen Energy, vol. 35, pp. 8371-8384, 2010.

[5] R.-H. Chen, "A Parametric Study of NO2 Emission from Turbulent H2 and CH4 Jet Diffusion Flames," Combustion and Flame, vol. 112, pp. 188-198, 1998. 
[6] A. R. Choudhuri and S. R. Gollahalli, "Characteristics of Hydrogen-Hydrocarbon Composite Fuel Turbulent Jet Flames," International Journal of Hydrogen Energy, vol. 28, pp. 445-454, 2003.

[7] M. İlbas, İ. Y1lmaz, and Y. Kaplan, "Investigations of Hydrogen and Hydrogen-Hydrocarbon Composite Fuel Combustion and Emission Characteristics in a Model Combustor," International Journal of Hydrogen Energy, vol. 30, pp. 1139-1147, 2005.

[8] T. Shudo, K. Omori, and O. Hiyama, "NOx Reduction and NO2 Emission Characteristics in Rich-Lean Combustion of Hydrogen," International Journal of Hydrogen Energy, vol. 33, pp. 4689-4693, 2008.

[9] J. H. Kent and D. Honnery, "Soot and Mixture Fraction in Turbulent Diffusion Flames," Combustion Science and Technology, vol. 54, pp. 383-397, 1987.

[10] N. Peters, "Laminar Diffusion Flamelet Models in Non-Premixed Turbulent Combustion," Progress in Energy and Combustion Science, vol. 10, pp. 319-339, 1984.

[11] Z. Qin, V. V. Lissianski, H. Yang, W. C. Gardiner, S. G. Davis, and H. Wang, "Combustion Chemistry of Propane: A Case Study of Detailed Reaction Mechanism Optimization," Proceedings of the Combustion Institute, vol. 28, pp. 1663-1669, 2000.

[12] E. Sozer, E. A. Hassan, S. Yun, S. Thakur, J. Wright, M. Ihme, et al., "Turbulence-Chemistry Interaction and Heat Transfer Modeling of H2/O2 Gaseous Injector Flows," in 48th AIAA Aerospace Sciences Meeting Including the New Horizons Forum and Aerospace Exposition, Orlando, Florida, 2010, pp. AIAA 2010-1525.

[13] M. Darbandi and M. Ghafourizadeh, "Extending a Hybrid Finite-Volume-Element Method to Solve Laminar Diffusive Flame," Numerical Heat Transfer, Part B: Fundamentals: An International Journal of Computation and Methodology, vol. 66, pp. 181-210, 2014.

[14] M. Darbandi and M. Ghafourizadeh, "Solving Turbulent Diffusion Flame in Cylindrical Frame Applying an Improved Advective Kinetics Scheme," Theoretical and Computational Fluid Dynamic, vol. 29, pp. 413-431, 2015.

[15] B. B. Dally, A. R. Masri, R. S. Barlow, and G. J. Fiechtner, "Instantaneous and Mean Compositional Structure of Bluff-Body Stabilized Nonpremixed Flames," Combustion and Flame, vol. 114, pp. 119 -148, 1998.

[16] S. M. Correa and A. Gulati, "Measurements and Modeling of a Bluff Body Stabilized Flame," Combustion and Flame, vol. 89, pp. 195-213, 1992. 